\title{
HABLAR POR OTROS: VARIACIONES DE LA PERSONIFICACIÓN EN DOS ODAS DE PABLO NERUDA ${ }^{1}$ \\ SPEAK FOR OTHERS: VARIATIONS OF THE PERSONIFICATION IN TWO ODES OF PABLO NERUDA
}

\author{
Andrea Casals \\ Pontificia Universidad Católica de Chile \\ acasals@uc.cl \\ Pablo Chiuminatto \\ Pontificia Universidad Católica de Chile \\ pchiuminatto@uc.cl
}

\begin{abstract}
Resumen:
El desafío que representa el diálogo intercultural y multicultural es otra de las dimensiones que deben asumir en la actualidad los estudios ambientales y ecocríticos. En el caso chileno estos temas han estado presentes en los últimos años producto del giro hacia el reconocimiento de las diferencias culturales de los pueblos originarios y las políticas culturales del Estado de Chile. En este artículo buscamos evidenciar este cambio a partir de dos odas de Pablo Neruda, escritas en la década del 50, que sirven de umbral para comprender un complejo horizonte poético, así como también uno retórico, cuando lo que busca el poeta, por medio de la denuncia, es hablar por otros.
\end{abstract}

Palabras clave: Neruda, poesía, alimentos, ecocrítica

\section{Abstract:}

The challenge to articulate intercultural and multi-cultural dialogue is another dimension that environmental and ecocritical studies must take on today. In the Chilean case, these themes have been present in recent years as a result of the turn towards the recognition of the cultural differences between original ethnic groups and the cultural policies of the State of Chile. In this article, we seek to bring forward this twist, based on the reading of two odes by Pablo Neruda, written in the 1950s, which serve as a threshold for understanding a complex poetic horizon, as well as a rhetorical one, when what the poet seeks - through the denunciation - is to speak for others.

Keywords: Neruda, poetry, food, eco-criticism

Recibido: 29/6/2017

Aceptado: 24/7/2017

\footnotetext{
${ }^{1}$ Este texto fue redactado en colaboración en el marco del proyecto FONDECYT Postdoc 3170134 de Andrea Casals y el proyecto VRI-UC-CCA-1419 de Pablo Chiuminatto.
} 


\section{"y no es sueño mi sueño sino tierra"}

P. Neruda

\section{Introducción}

Las odas elementales y celebratorias, en lenguaje simple y directo, junto a la personificación de objetos cotidianos son recurrentes en la obra de Pablo Neruda. Esta reiteración es consistente con las convicciones políticas del poeta, en tanto festejan la vida material del ser humano en un sentido que es al mismo tiempo profundo y trascendental. En las odas a la "Araucaria araucana" (1955) y al "Trigo de los indios" (1955) observamos que la figura retórica de la personificación cobra matices dramáticos que nos remiten otra figura, la prosopopeya. Elementos retóricos que, en este caso, representan a un supuesto ausente con rasgos épicos, que en estas odas celebran las hazañas de un pueblo que el poeta representaría por interpósita persona, en un gesto a la vez poético y político. Desde una perspectiva histórica, en Chile, los pueblos originarios han estado marginados del proyecto de nación y así lo entiende Neruda. Una relectura de estas odas desde la prosopopeya parece pertinente cuando a más de sesenta años de su publicación, los protagonistas de estos versos siguen viviendo situaciones como "la omisión lesiva de la inacción política" del Estado (Soto, Fuenzalida y Bresciani 36), y el "extendido desconocimiento de los derechos del pueblo Mapuche" (Madero y Cano 38) a pesar de los convenios internacionales recientemente suscritos por el Estado chileno.

La palabra prosopopeya está formada por la raíz griega prosopon, persona o cara y poiein que significa realizar. En este sentido, el concepto no se limita a personificar a un ausente, sino que lo visibiliza, le da un rostro particular. Esta forma de figuración contribuiría precisamente a contrarrestar la borradura ejercida sobre los pueblos indígenas de nuestro país en general, a la vez que le confiere agencia, en tanto esta persona (o grupo) puede realizar, llevar a cabo acciones, hace o participa por medio de su ingreso en el discurso cultural.

En Confieso que he vivido Neruda se representa a sí mismo como un gozador de los alimentos, ávido de todo. En una imagen poética que lo acerca a figuras míticas, declara: "Me comería toda la tierra. Me bebería todo el mar" (Confieso 2a , 365). En A la mesa con Neruda, Aída Figueroa matiza esta representación que propone el poeta, dice: "Pero [Neruda] ¿fue realmente un émulo de Pantagruel? No exactamente [...] Algunos sostienen 
que era un gourmand. "Más bien considerémoslo un gourmet" $(11)^{2}$. Si bien Neruda alaba y le canta a alimentos cotidianos en muchas de sus odas ${ }^{3}$, lo populares que son, y la fama de sibarita que proyectó, no hay un corpus de crítica que analice específicamente aquellas odas vinculadas a los alimentos. Hace ya dos décadas, en la revista Literatura y Lingüística Victoria McCard escribe sobre el banquete nerudiano, ( ${ }^{\circ} 10$ Santiago 1997) relacionándolo con el texto clásico de Mijail Bajtin La cultura popular en la Edad Media y Renacimiento. En su artículo, McCard describe las odas elementales como la culminación de la poetización de los alimentos en Neruda, desde la perspectiva del rol de los alimentos en la fiesta popular. Gesto que además se encuentra en otros poetas de Chile y que con distintos énfasis recorre el imaginario poético de forma transversal (Sepúlveda 201). En los poemas de Neruda la fiesta se manifiesta como banquete, mesa compartida que celebra a la comunidad, dispuesta en un "gran mantel" para honrar a todos los que deseen compartir. Esa es la contraseña para ser convidado, más que nada una disposición. Sin embrago, en las odas que nos proponemos analizar, veremos que el poeta va más allá y realiza una denuncia, habla por otros ausentes.

Cuando iniciamos esta investigación, reunimos un corpus de odas de Pablo Neruda que en una primera instancia hablaban de alimentos relacionados con los pueblos originarios americanos: el maíz, la papá y el "trigo". No obstante, la tesis que vinculaba estos tres poemas se debilitaba, ya que el trigo no es un cereal originario de América y por eso mismo parecía obstinado que el poeta insistiera en el adjetivo con que construye el título de la oda al trigo de los indios. Por una parte, surgía la ambigüedad con la quínoa, hoy denominada "trigo de los incas", que es efectivamente un cereal originario de Los Andes, principalmente de la zona de Perú y Bolivia. Pero el poema no trata de la quínoa, sino de la forma en cómo el trigo (exótico) es otro medio de explotación del pueblo Mapuche. Por otra parte, la

\footnotetext{
${ }^{2}$ En el diccionario Cambridge online un gourmet es un conocedor de los alimentos y la cocina, que disfruta comiendo alimentos de calidad ('a person who knows a lot about food and cooking, and who enjoys eating high-quality food'); un gourmand es aquel que disfruta comiendo en grandes cantidades ('a person who enjoys eating large amounts of food').

${ }^{3}$ De acuerdo a Juan José Sáez:

Neruda encuentra en sus odas una libertad expresiva y temática, una fluidez lírica y una especie de euforia [...] El ciclo de las odas [...] es un vagabundeo poético que hace del mundo entero su objeto, [...] Neruda llama a estas odas elementales por muchos motivos, aludiendo en primer lugar a la forma simple y directa en el discurso poético, [...] y también en razón de los temas de que se ocupa. (8)

4 'Oda a la papa' y 'Oda al trigo de los indios' publicadas en Nuevas odas elementales (1955) 169-174; 'Oda al maíz’, publicada en Tercer libro de las odas (1955 - 1957).
} 
denuncia resulta contradictoria con la noción elegíaca que el tono de esta oda propone, básicamente en una fórmula contradictoria entre celebración y desconsuelo.

Otra clave para resolver esta diferencia entre las tres odas a los alimentos en relación a los pueblos originarios la entregó la "Oda a la araucaria araucana", que explícitamente canta al fruto de esta, al piñón. El título del poema está tomado del nombre científico de esa especie en particular, que se da en la zona del norte de la Patagonia de Argentina y centro sur de Chile. La precisión de este título, araucaria araucana, en oposición a la ambigüedad del "trigo de los indios", establece una distinción respecto de las otras coníferas de este tipo y que se encuentran en Uruaguay y Brasil o las de Oceanía, endémicas de Australia, Nueva Caledonia y Nueva Zelanda. En consecuencia, el diálogo entre ambas odas de Neruda plantea la posibilidad de una comparación que permite comprender mejor el rol que el poeta le da a estos elementos de la naturaleza, su relación con los pueblos originarios y la figura de la prosopopeya que está implícita en las odas: “Oda al trigo de los indios” y "Oda a la araucaria araucana".

\section{II “Oda al trigo de los indios"}

Como su nombre lo indica, los poemas que analizaremos siguen el modelo de una oda libre. Las odas de Pablo Neruda son conocidas porque en ellas el poeta le canta a objetos cotidianos, concretos y materiales acordes con la propuesta estética de Neruda. En el poema "Estatuto del vino" el poeta dice: "Hablo de cosas que existen, Dios me libre / de inventar cosas cuando estoy cantando" (123). Asimismo, en el prólogo de la edición Debolsillo de las Nuevas odas elementales y el Tercer libro de las odas, Sergio Ramírez explica:

Las odas están escritas en este homenaje de felicidad. La mera contemplación de las cosas sencillas, su alabanza exaltada, se convierte en un acto de optimismo, y un llamado a los seres humanos para congregarse de manera solidaria alrededor de los humildes portentos de la creación [...] [E]n las odas las gracias no están dirigidas a la divinidad que las provee, sino a las manos que segaron el trigo, y a las que lo molieron, a las que amasaron la masa y encendieron el horno hasta crear la fragante y esponjosa maravilla (12).

\footnotetext{
5 'Oda a al araucaria araucana', publicada en Nuevas odas elementales (1955) 14-18.
} 
En este análisis, veremos que el tono de estas dos odas en particular, sin embargo, no es del todo celebratorio como anuncia Ramírez en el prólogo, ni protagonizan la fiesta popular que describe McCard. Como hemos mencionado, "Oda a la araucaria araucana" no le canta a la araucaria misma, sino que le canta al piñón, el fruto. En esta misma línea y tomando en cuenta que el piñón es parte de la dieta alimentaria básica de los Pehuenche ${ }^{6}$, es coherente suponer que también el "trigo de los indios" al que se refiere la voz del hablante sea el fruto de la araucaria, el piñón. De tal forma, vemos una equivalencia entre trigo, como elemento fundamental para la elaboración del pan que es, a la vez, un alimento básico en la sociedad occidentalizada y el piñón, sustento de la etnia a la que canta. No obstante, hay que recordar que el trigo llega a América con los conquistadores, por lo que hablar de "trigo de los indios" presenta una contradicción con la intención de la oda, ya que la introducción de este alimento exótico implica otra forma de borradura del pueblo Mapuche, en tanto impone una dieta basada en el cultivo a una cultura más bien recolectora. A pesar de estas tensiones, la concordancia con la poética de Neruda, establece el cruce entre la cosmovisión Mapuche y el juego filológico que ofrecen sus versos como señala Ziley Mora: "cual granada de semillas de mundos contiguos y asociados, estallan en significado" (72); asimismo, estas odas encierran múltiples asociaciones que nos disponemos a revisar.

Algunos atributos comunes de ambos alimentos, el trigo y el piñón, radican en la relación entre el alimento como nutriente y su rol en el acto social de comer. En palabras de De Certeau: "Comer sirve no solo para conservar la maquinaria biológica del cuerpo, sino para concretar una manera de relación entre las personas y el mundo" (189). Es decir, perfila una manera de ser en el tiempo y en el espacio para la comunidad. Asimismo, "la intimidad de la comida forma parte de lo que mantiene unidos a aquellos que comen [juntos]" (Korsemeyer 253). En este sentido, el alimento es como la lengua, ya que la identidad y los lazos se generan a partir del alimento que se comparte y de la lengua común. Ambos — la lengua y los alimentos - poseen un componente temporal y territorial importante: la lengua y el alimento que esa comunidad recolecta o cultiva constituyen un mismo hábitat. En ambos casos, hay una dimensión espacial y temporal común que estos poemas recuperan, además del componente local propio de las prácticas tanto sociales como religiosas.

\footnotetext{
${ }^{6}$ Nótese que Neruda utiliza la palabra "indios" en términos genéricos, no hace una distinción entre Pehuenche y Mapuche; no obstante, es frecuente hablar de Mapuche en términos generales para referirse tanto al pueblo Mapuche (gente de la tierra), como a Pehuenche (gente del pehuén) o Huilliche (gente del sur).
} 
En De Certeau vemos que el alimento se asocia a tres niveles históricos: natural, material y económico. En la fase natural, hay un vínculo directo con la tierra: comen lo que recolectan de lo que el entorno ofrece. Así en el campo los pobres se alimentarán de lo que encuentren en el entorno (ya sea lo que crece naturalmente o se cosecha), en la ciudad recolectan lo que sobra (incluso los despojos de los otros). En el caso Pehuenche, justamente el fruto de la araucaria constituye una recolección fundamental para su dieta y su cosecha es un ritual. De manera que la obligación de cultivar el trigo se vuelve impostada y a-cultural.

En estas odas, el poeta parece estar hablando de otra cosa, y no solo cantándole al alimento. Aquí el alimento no presenta solo la cosa y su connotación de nutriente sino además a la popular imagen de sentarse a una mesa. En Neruda, la matriz ${ }^{7}$ de la metáfora de la mesa larga es recurrente. En el poema "El gran mantel”, es la justicia, que se manifiesta en la posibilidad de sentarse a la misma mesa todos quienes son capaces de compartir. En estas odas no se observa tampoco "la mesa feliz" destacada en Comiendo en Hungría "donde aprend[ería] el mundo a comer" (91). El alimento en estos poemas se acerca más a la "Oda al pan” (156), donde el pan es metáfora de una revolución que se hace entre todos, en un acto performativo y premonitorio, donde comer juntos es proceso y fin para alcanzar la justicia.

Esta última relación permite un paralelo con un hecho reciente ${ }^{8}$, el 27 de agosto de 2010 uno de los 33 mineros atrapados en la Mina San José en Copiapó declara: "la familia minera no es la familia que conocimos hace 100 o 150 años atrás, hoy día el minero es un minero educado, es un minero que se puede hablar con él. Es un minero que usted puede sacar pecho y se puede sentar en cualquier mesa de Chile" (AFP). Lo que la declaración señala, es que los mineros se han constituido en un interlocutor válido, que han salido de su posición de subalternos, que han entrado al sistema al ser educados, y por tanto, pueden "hablar" y "ser oídos". La identificación con la mesa como metáfora del espacio público hace referencia, por otra parte, a la remisión al espacio doméstico y privado como rearticulación real de lo público. Esta es también la situación que proclama Neruda en "Oda al pan" (156). Tras la revolución que anticipa el poeta -que de alguna manera pone en tensión con los matices que la misma revolución comunista anunció y que en muchos casos logró,

\footnotetext{
${ }^{7}$ Parafraseando a Riffaterre, un poema resulta de las transformaciones de la matriz, que es el motor que produce la derivación en el texto; la matriz puede ser resumida en una palabra que no está presente en el texto y siempre se actualiza a través de variaciones sucesivas. (19 - 21)

${ }^{8}$ Parafraseando a Riffaterre, esta relación con la actualidad constituye un hipograma, que es un sistema de signos que contienen a la matriz de manera latente (23 -25).
} 
Andrea Casals, Pablo Chiuminatto. Hablar por otros: Variaciones de la personificación en dos odas de Pablo Neruda

pero con costos que finalmente también significaron una crisis- Neruda busca el mismo cambio que simbólicamente provoca el episodio de los 33 mineros: promover un espacio digno (en tanto condiciones laborales en este caso) y el derecho de los trabajadores a ser escuchados. En A Critique of Postcolonial Reason, Gayatri Spivak argumenta que cuando se extiende una línea de comunicación entre un miembro del grupo de los subalternos y el circuito de los ciudadanos o la institucionalidad, el subalterno ha sido insertado al largo camino de la hegemonía (2115); este es el gesto que el minero reconoce con la metáfora de la mesa. Recordemos, como señala Jaime Concha, "la mina es para Neruda la noche de la historia" (94).

En contraste con estos mineros de comienzos del siglo XXI que hablan por ellos mismos o las organizaciones que los representan, en el momento de la enunciación de las odas que analizamos, la organización del trabajo en el mundo rural en Chile en general -una década antes de la Reforma Agraria- el pueblo Mapuche no tenía, tal como hoy, una representación proporcional en las instancias civiles y gubernamentales de alto nivel. Esto, a pesar de que desde el año 1924 -y sin los mecanismos de cuota política que actualmente conocemos- importantes miembros de comunidades Mapuche habían logrado escaños en el parlamento, como Francisco Melivilu (1924 diputado Partido Demócrata) el primero y posteriormente Manuel Manquilef (1926 diputado Partido Liberal) y en 1932, Antonio Huenchullá, del Partido Demócrata) ${ }^{9}$. Al momento de escribir Neruda sus odas, a pesar de estos avances en el ámbito político, los pueblos originarios, y en general los trabajadores, se encontraban en otra posición de enunciación, aquella que no puede decir ni ser leída, la posición de un grupo subalterno. Por esta misma razón, en Chile los movimientos sociales de izquierda y de derecha adquirieron rápidamente un rol que alcanza al mismo Pablo Neruda, quien es electo Senador de la República por las regiones de Tarapacá y Antofagasta en 1945 y que luego lo llevará a militar activamente en el Partido Comunista hasta que en el año 1969 incluso llega a ser precandidato a la presidencia de Chile.

En A Critique of Postcolonial Reason, Spivak se pregunta si el subalterno puede hablar. Define al sujeto colonial "otro" como el subalterno (2115) que está al otro lado de la diferencia (2124). Subalternos serían pues todas aquellas personas que sin especialización, es decir ni académicos ni políticos, para quienes la episteme opera su función de programación

\footnotetext{
${ }^{9}$ José Bengoa, Historia del pueblo Mapuche siglo XIX y XX. Santiago: Lom, 2000. Ver, 331ss.
} 
silenciosa (2116). No obstante, de acuerdo a Spivak, es necesario reconocer que el sujeto subalterno es heterogéneo (2118) y que es justamente la diferencia lo que lo identifica. El subalterno no puede hablar porque no encuentra o no tiene un lugar de enunciación, no puede decirse a sí mismo; no puede hablar tampoco porque no puede ser oído ni leído, y en muchos casos, sus actos de protesta no logran ser decodificados ni siquiera por sus pares. Sin embargo, Spivak agrega que a pesar de esta condición de mudez e invisibilidad, tampoco es una solución que el ámbito político e intelectual se abstenga de representarlo (2119). La pregunta que surge luego es si es posible suponer que cuando se busca dar voz a estos grupos marginados, realmente se está hablando por ellos. Es ahí donde se cruza el principio político de la representación con las nociones retóricas que implican dar voz o prestar voz a otros. En el caso de Neruda, suma en las figuras conocidas como metagogé y prosopopeya o personificación con la perspectiva política que puebla la obra del poeta. Tal como señala Jaime Concha, cuando reconoce que "es posible postular una total correspondencia entre la poesía de Neruda y su posición política marxista" (95). Así, ambos conceptos retóricos son cercanos, básicamente, metáfora por la cual un objeto inanimado adquiere animación o vida, sin que necesariamente sea antropoformizado.

En estas odas Neruda busca hablar por los mapuches, pero lo hace a través de dos elementos de la naturaleza: el trigo exógeno y el piñón originario. La voz del poeta reconoce que viene de lejos ${ }^{10}$; como el trigo, él es un forastero. Al inicio de la "Oda al trigo de los indios" el hablante señala, "yo nací lejos, lejos". No obstante, el hablante-niño quiso identificarse con los Mapuche, hasta que le mostraron que él también era extranjero. El poema relata que el último cacique no le sonrió porque era extranjero. Consciente de esta diferencia, el hablante termina la oda reconociéndose como poeta y ofreciendo su voz para representar al pueblo Mapuche: “otro / poeta / viene / cantando: / [...] / Otro / poeta / llega / ahora a defender $[\ldots] /[\operatorname{los}] \operatorname{sacos} /$ silenciosos / [ ...] / pidiendo patria / para sus hermanos. Ese otro poeta, ya no es la voz del conquistador que plasmó la épica del poema La Araucana de Alonso de Ercilla a fines del siglo XVI. En este sentido, Neruda además se adelanta a Spivak, 50 años antes de que ella enuncie la pregunta: “¿puede hablar el subalterno?”. Neruda se da cuenta que el pueblo Mapuche ha sido largamente silenciado y que no solo no

\footnotetext{
${ }^{10}$ En Confieso que he vivido $\left(1^{\mathrm{a}}\right)$ Neruda describe su llegada a Temuco desde Parral y se enuncia como un yo diferente a los Mapuches que no vivían en la ciudad, pero la visitaba para vender sus productos I, 15-43.
} 
puede hablar, sino que no hay alguien que lo escuche. Así, desde su posición privilegiada como poeta, intelectual y político reconocido, Neruda crea una voz de enunciación que se ofrece para hablar por ellos, atendiendo en anticipado la advertencia de Spivak, de no renunciar a la posibilidad de representar al subalterno. Aunque no advierte la operación biopolítica que representa la figura retórica en sí, hablar por otro es también traducirlo, es impostar la voz de otro que nunca será igual a lo que puede decir de sí ese otro en tanto otro. Por lo mismo, aunque la intención del hablante pueda intentar una acción poética concreta, no por eso la connotación política alcanza su objetivo plenamente. También aquí podría haber una voluntad de apropiarse de un discurso de otro y por lo tanto de una alteridad instransferible.

Este es uno de los peligros centrales que ha vivido el proceso de acuerdo con los pueblos originarios y que ha quedado de manifiesto durante la consulta indígena realizada durante el gobierno de Michelle Bachelet (2015) una vez suscrito el Convenio $169^{11}$, y luego durante la redacción del proyecto de ley que crea el "Ministerio de las Culturas, las Artes y el Patrimonio”. Este proyecto de ministerio, aún en votación en el Congreso, desde su mismo nombre intenta asegurar la polifonía cultural acorde con las voces que promueven la plurinacionalidad $^{12}$, pero que, contradictoriamente, la institución busca acoger y reducir a una administración centralizada por el Estado de Chile bajo un ministerio con servicios regionales (Chiuminatto 149).

\footnotetext{
${ }^{11}$ El Convenio 169 de la OIT (Organización Internacional del Trabajo) sobre Pueblos Indígenas y Tribales en Países Independientes, es un tratado internacional adoptado en Ginebra en 1989; fue ratificado por Chile en 2008; y está vigente desde septiembre de 2009: “[...] establece el deber para el Estado de Chile de consultar las medidas legislativas y administrativas susceptibles de afectar directamente a los pueblos originarios, estableciendo procedimientos apropiados de consulta a los pueblos interesados, de buena fe y con la finalidad de llegar a un acuerdo o lograr el consentimiento acerca de las medidas propuestas". El convenio 169 de la OIT, regula además materias relacionadas con la costumbre y derecho consuetudinario de los pueblos originarios, establece ciertos principios acerca del uso y transferencia de las tierras indígenas y recursos naturales, junto con su traslado o relocalización. Finalmente, se refiere a la conservación de su cultura y a las medidas que permitan garantizar una educación en todos los niveles, entre otras materias". (http://www.consultaindigenamds.gob.cl/qconvenio.html)

${ }^{12}$ El concepto de plurinacionalidad se instala entre agrupaciones indígenas a comienzos de los años 1990s y cobra fuerza a partir del reconocimiento plurinacional de Guatemala, Ecuador y Bolivia (Soto et al.)
} 
En oposición a este gesto audaz y riesgoso, en ese contexto, al mismo tiempo de ofrecerse a hablar por el subalterno, llama la atención que Neruda escoja siempre voces castellanas y nunca voces en mapuzungún. ${ }^{13}$ ¿Por qué lo hace? Recordemos que, por definición, el subalterno no solo no puede hablar, sino que tampoco puede ser leído u oído. En consecuencia, si Neruda se ofrece a representar al pueblo Mapuche, estratégicamente requiere que su voz sea escuchada, y en consecuencia su lengua debe ser aquella con la cual sea posible establecer ese nexo del que habla Spivak. Asimismo, si el hablante desea que la situación del pueblo Mapuche sea comprendida y divulgada, parece eficiente hablar de trigo y no abiertamente de piñón, ya que, en el imaginario chileno, trigo se asocia a pan, y pan a alimento básico. No obstante, esta decisión también es un riesgo ya que nombrar los pueblos por el nombre colonial, "indios" en este caso, impuesto desde fuera de la comunidad, puede ser entendido como otro gesto más de borradura desde el poder hegemónico. Finalmente, parece pertinente recalcar, no obstante, que en estas odas no está "hablando" el pueblo Mapuche, sino que está siendo "representado" por el poeta que se enuncia como un testigo de la situación que menoscaba a dicho pueblo.

De acuerdo a Miguel Yaksic, en el 2009 "lo que la prensa ha denominado 'conflicto Mapuche' no ha sido capaz de [mostrar el] fondo del problema. Porque han enfrentado el asunto en términos de pobreza y falta de recursos cuando lo que ha ocurrido ha sido una sistemática práctica de desconocimiento de una identidad colectiva particular” (38). Para Yaksic el conflicto se remonta al discurso que aprendimos en las clases de historia en la escuela, donde se nos habló de la "pacificación de Arauco", discurso reforzado durante la Dictadura Militar (1973-1990). Este gesto de planificación cultural y lingüística buscó eliminar del imaginario "la idea de la nación o pueblo Mapuche", desarticulando además el tejido social comunitario al forzar la tenencia individual de la tierra. Para Yaksic,

[e]l problema de fondo ha radicado entonces en el daño provocado a una subjetividad que se ha querido borrar [...] Los Mapuches [sic] han visto por siglos cómo su identidad, su particular modo de ver el mundo y de vivir la vida, ha sido negada; han visto cómo la tierra y las costumbres que un día les pertenecieron les han sido arrebatadas $(38,39)$.

\footnotetext{
13 Antes que Neruda, Walt Whitman y Gabriela Mistral, ambos leídos y admirados por Neruda, incorporan voces indígenas en su poesía (por ejemplo, Mistral en el poema "Maíz" en Tala y Whitman nombrando Long Island, su pueblo natal, por el nombre indígena, Paumanok en Hojas de Hierba, 608).
} 
Andrea Casals, Pablo Chiuminatto. Hablar por otros: Variaciones de la personificación en dos odas de Pablo Neruda

En este sentido, José Bengoa en el artículo "Chile y los Mapuches: asignaturas pendientes" compara la Guerra del Pacífico (1878) y la Pacificación de Arauco (1881). Ambas instancias de expansión territorial casi paralelas en las cuales participó el mismo ejército, establecen nuevas fronteras tanto para el exterior hacia el norte y otra, al interior, hacia el sur. Bengoa escribe: "En ambos [casos], la fuerza estableció el derecho y los vencidos debieron acatarlo" (41), fijando fronteras desde la perspectiva del vencedor, reconociendo jurídicamente territorios para el más fuerte y no para los primeros habitantes.

En las dos odas que analizamos se cristaliza esta situación y las denuncias aún vigentes $^{14}$. En "Oda al trigo de los indios" el hablante describe la situación de la cual es testigo, repitiendo términos que denotan la pobreza en la que viven las comunidades, tales como: "el último, el menguado, / el harapiento / oro / de la pobre Araucanía. / [...] /dura cara, / ralos bigotes, / ponchos / menoscabados," (170). Y, paralelamente, describe una realidad en la que algo se está perdiendo, gastando y diluyendo: “y las pobres espigas / desgranaban / el último, / el hambriento, / el raído /oro / del pan / de la pobre Araucanía" (170-171). El hablante sin duda muestra la pobreza, pero no limita el problema a la merma material, como acusa Yaksic. El hablante muestra que tampoco lo que se está "desgranando" y lo que está "raído" es solo el territorio, eso el poeta lo dice abiertamente más adelante: "Recuerdo / aquellas tierras /saqueadas / por jueces / y ladrones, / la cosecha, / los indios / del verano / con menos tierra y trigo /en cada estío" (172). El testigo muestra que aquello que está siendo "menoscabado" es justamente la identidad Mapuche, no sólo por su relegación a territorios lejanos y pobres para el cultivo, sino por la borradura que se hace de su cultura al imponerles forzosamente argumentos jurídicos proclamados desde el Estado nación: “arrinconándolos / con sentencias, providencias, / exhortos” (172); al imponer también una asimilación con la cultura dominante utilizando dádivas hipotecadas: "los curas / aconsejándoles el cielo / con mejores terrenos / para el trigo" (172). Problematizando el rol de la iglesia colonial, la que conoció Neruda y la actual, siguiendo el diagnóstico de la propia Comisión de Justicia y Paz de la Conferencia Episcopal, hoy podemos entender las "políticas estatales centradas en lo político-judicial junto a la implementación de modelos desarrollistas agresivos y ajenos al territorio" (Soto, Fuenzalida y Bresciani 35). Este último factor resulta

\footnotetext{
14 Nótese que Neruda escribe estas odas entre 1955 y 1957, alrededor de 75 años después de la llamada Pacificación de Arauco, hoy hace ya más de 60 años.
} 
otro elemento que contribuye a la injusticia ejercida sobre los pueblos originarios en general, a lo que se suma la militarización, puntualmente, del conflicto entre el "Estado chileno, grandes agricultores y empresas forestales", y "sectores Mapuche significativos" (Soto, Fuenzalida y Bresciani 35). Entonces, desde la mirada actual, observamos que justamente, en estas odas Neruda logra evidenciar una situación de violencia lenta que de acuerdo a Rob Nixon es difícil de representar precisamente por su falta de espectacularidad mediática, así como también debido a sus múltiples causas y efectos dispersos en el tiempo y en el espacio. Es quizás por ello, además de su propia agenda política, que la prensa se enfoca en los hechos de violencia puntuales como enfrentamientos y quemas, más que en cualquier otro factor del proceso. De acuerdo a los jesuitas de la comunidad de Tirúa, Soto, Fuenzalida y Bresciani, existe una "triste e injusta relación mediática entre el pueblo Mapuche y los recientes incendios, que invisibiliza el rol de la industria forestal en el conflicto" (34).

Volviendo a los poemas, Giorgio Agamben, plantea la posición de enunciación desde la de un testigo que muestra la vivencia del pueblo Mapuche, una voz que muestra los "restos" de una cultura, lo que va quedando de ella y por ello precisa de la prosopopeya (143). En las odas de Neruda el hablante ha informado al lector que de niño visitaba a las comunidades Mapuche en las veranadas $^{15}$, y que de año en año veía como sus tierras y sus cosechas iban mermando. En este sentido, el sujeto de enunciación se presenta como un testigo que puede dar testimonio por aquellos que no pueden hablar ya que, efectivamente, los conoce de cerca. El hablante presenta los restos de esta cultura como espectros, mencionándolos dos veces en la cuarta estrofa del poema: "y los sacos / de trigo / como espectros / de la antigua Araucanía," (171); y "los sacos, los espectros de mi patria" (172). En la primera alusión, los sacos son espectros, es decir que en el tiempo de la enunciación, lo único que va quedando es una sombra en la versión traducida de la idea que el estado-nación proyecta sobre el indígena. Idea compleja que se reafirma en la segunda alusión, donde los sacos ya no son "como" espectros, sino que son, definitivamente, espectros. De algún modo la obligación a la que los somete la diferencia cultural monopoliza la percepción de esa "otra" cultura bajo el prisma de lo propio. Es decir, al ejercer la traducción, el solo gesto

\footnotetext{
${ }^{15}$ Las veranadas son praderas de pastoreo estacional, que permanecen la mayor parte del año cubierta por la nieve. Particularmente los Pehuenche, pasan el inverno -o invernada- en el pie cordillerano, y suben con sus animales a las praderas naturales durante el verano. Al final del verano, antes de bajar nuevamente, recolectan el piñón.
} 
convierte al otro en algo comprensible a través de los valores y el lenguaje propio. En este caso los bienes, la posesión de la tierra y una forma de felicidad que no necesariamente es congruente con la cultura de esas comunidades. No buscamos con esto relativizar las condiciones de pobreza en la que las mismas comunidades Mapuche se han descrito, pero sí, generar la distancia de los significantes que cada cultura proyecta cuando identifica los signos de riqueza espiritual o material de otra cultura. El cambio interesante en esta repetición de la noción de espectros es que la antigua Araucanía ahora es la patria. En otras palabras, la raíz de la patria nerudiana estaría en la región de la Araucanía, la Wallmapu, y sus primeros ocupantes. Cuestión que hoy más que nunca, por la discusión de la Consulta Indígena (Convenio 169 de la UNESCO) y la conformación del diseño de un ministerio de culturas -en plural- y un futuro Ministerio Indígena, ha quedado de manifiesto. Al menos nueve etnias distintas para un solo Chile, cada una pensando su propio territorio como una dimensión que va más allá de la tierra y de la esfera económica y social ${ }^{16}$.

Estas odas evidencian así la comprensión del poeta de aquella multidimensionalidad de la situación vivida por el pueblo Mapuche. La idea de espectros permite detenernos ahora en esa otra imagen, los sacos: 'Los sacos / se llenaban / de cereal, [...] y los indios / sentados / como sacos / de tierra / y los sacos / de trigo / como espectros / de la antigua Araucanía, [...] y abajo / tierra pobre y lluviosa, / trigo pobre / y los sacos: / los espectros / de mi patria" (171-172). El trabajo de los indígenas ha llenado de cereal los sacos, y han terminado extenuados como "sacos de papas"17. En este caso, en vez de que el campesino trabaje para obtener su alimento, en la denuncia de la explotación de la clase obrera y campesina, Neruda muestra que el trabajo los ha consumido, convirtiéndolos en una figura fantasmal. La impresión negativa que transmite el hablante también puede remitir a esa forma de desencuentro de una sociedad recolectora y comunitaria enfrentada a una, como bien ha descrito Byun-Chul Han, "sociedad de rendimiento" (25); donde por opción de sobrevivencia "se ejerce voluntariamente una autoviolencia para protegerse de una violencia mucho mayor, que sería mortal” (17). La conquista fue testigo de esa operación colectiva e individual en distintos grados de silencio e inacción.

\footnotetext{
${ }^{16}$ Ver, "Informe de la Comisión de Cultura, Artes y Comunicaciones recaído en el proyecto de ley que crea el Ministerio de Cultura", Cámara de Diputados, 14 de junio de 2016, Boletín 8938-24.

${ }^{17}$ En el poema no se mencionan sacos de papas, pero en lenguaje popular se utiliza la expresión o cliché como saco de papas, para referirse a una persona que está agotada, y esta es justamente la idea que evoca el poeta en estas líneas.
} 
Considerando que el pueblo Mapuche es, en su voz, "la gente de la tierra", otra repetición interesante de revisar para interpretar estas odas es la mención a la tierra: "se movía la tierra"; "mi tierra verde y roja"; "tierra, tierra, canelos"; "como si la tierra fuera una sola rosa"; "sacos de tierra"; "aquellas tierras saqueadas"; "con menos tierra y trigo"; "aquella tierra con ramos de avellano"; "de quien es la tierra?". Y otras alusiones a tierra: "heridos territorios"; "mejores terrenos", "pidiendo patria”. Si vinculamos esta secuencia con la anterior, en el mismo poema, y nos fijamos en "tierras saqueadas", observamos que esta idea cruza todo el poema: las tierras, el trabajo y el alimento de los Mapuche se meten en "sacos" y como el "hombre del saco" se lleva a los niños a lugares desconocidos. Todas estas preciosas pertenencias, todo su "oro" es usurpado, incluyendo su tierra, y con esta, su identidad, reforzando la idea de que a los Mapuche no les queda nada, ni tierra ni lengua, y casi no queda nada de ellos mismos, apenas si son un fantasma de sí mismos, solo quedan sus propios restos.

Por otra parte, el "saco robado" recuerda la figura del Imbunche:

[e]n el imaginario de [la cultura Mapuche] y en el universo chilote el Imbunche representa un niño sin bautizar [...] robado y regalado a los brujos [...] El niño [...] sufre deformaciones y torturas que lo convierten en una mezcla de humano y animal. [...] También se sabe que se le obstruyen todos los orificios del cuerpo, excepto la boca. [Y] jamás escucha una voz humana, por lo cual crece sin aprender a hablar (Montecino 244-245).

El Imbunche, representado en los campesinos Mapuche que terminan la jornada de la trilla como sacos, es una figura que sintetiza la idea del subalterno sobre el cual se ha ejercido una violencia: es el sujeto colonial, "no bautizado" (diferente a la cultura dominante). Medio humano, medio animal, incivilizado y bárbaro (no europeo) está fuera del sistema, viviendo entre brujos, con sus labios cosidos. En un paralelo con un elemento central de la novela chilena del siglo XX, José Donoso re-escribe la figura del Imbunche en El obsceno pájaro de la noche donde la bruja o Imbunche es una "representación del sujeto excluido de los procesos de modernización [...] un sujeto otro [construido] por discursos que detentan el poder" (Schoennenbeck 162 y 165). Siguiendo esta lógica, esta oda presenta un sujeto convertido en saco después de haber sido explotado y saqueado por la modernidad representada por la terrible máquina trilladora que ensaca automáticamente y se lleva el producto del trabajo del campesino indígena a las zonas urbanas. 
Observemos ahora la siguiente repetición en torno al trigo, la cosecha y la trilla. Cuando el hablante emplea la palabra "cosecha", describe de forma sinestésica una situación incómoda: "Era / la cosecha del trigo, / paja / seca / volaba,"(170), el trigo se ha convertido en algo árido que no se puede agarrar, es solo paja seca. El léxico en torno a la "trilla" tampoco evoca una situación agradable: "la trilladora / ardía [...]” (170); "en el círculo / del trigo / un grito / o una / quemante carcajada" (171); "Los sacos / se llenaban / de cereal, de pronto / la trilladora / detenía / su jadeo"; "y los sacos / de trigo / como espectros" (171); "con menos tierra y trigo / en cada estío, mirando la terrible / trilladora" (172). En otras palabras, la situación aludida es como uno de los círculos del Infierno que Dante imagina en la Divina Comedia: hay espectros, gritos y jadeo, es terrible y quema (I vv. 114-117). Nótese que esta imagen contrasta con el relato de Pascual Coña, donde "los Mapuches antiguos se ayudaban entre sí [...] trabajaban de mancomún, terminadas esas faenas daban principio a sus comilonas festivas" (138), donde la cosecha y trilla es un trabajo, acompañado de bailes y comida compartida (161-9). Para el mismo Neruda en Confieso que he vivido, la trilla es reportada como un evento feliz y comunitario (40), y en la "Oda al Trigo": "[E]n cada estío mirando la terrible / trilladora" (172) refuerza la idea de que en año a año, al subir a la veranada el poeta observa la reducción no solo del territorio sino de su cultura. Asimismo, los Mapuche son testigos de cómo la máquina abstracta de la modernidad que se les impone y la "terrible trilladora" viene a segar los frutos de su tierra y su trabajo ${ }^{18}$. Hoy, recurriendo nuevamente a un paralelo con la actualidad, lo que se les ha impuesto es la industria forestal que empobrece la tierra con monocultivos casi exclusivamente. Esta transformación que puede parecer solo técnica, debilita las comunidades, segrega y recluye a los habitantes en la contemplación del avance de especies exóticas, como el pino insigne, que, con su acelerado tiempo de crecimiento, a diferencia de las araucarias, permite acceder con los cultivos al mercado, pero no favorece la sobrevivencia de la cultura a la que está vinculada esa tierra.

\section{III “Oda de la araucaria araucana”}

En la "Oda de la araucaria araucana" vemos que el poeta elige un nombre de archivo para el poema, su nombre científico; no el nombre con el cual los Pehuenche la designan,

\footnotetext{
${ }^{18}$ Nótese que en el poema en ningún momento se alude a la hoz que se utiliza en la cosecha manual, siendo la hoz, símbolo en la bandera comunista, de la unidad proletaria, entre el trabajador (martillo) y el campesinado (hoz). Tampoco a la guadaña, tradicionalmente asociada a la muerte o el tiempo como límite de lo humano.
} 
pehuén. En "El archivo y el testimonio" Agamben postula que si el texto presenta marcas de archivo, es porque hay algo de lo que se quiere hablar, pero que no está enunciado, o es enunciado por el silencio (143). Del mismo modo, cuando el poeta escoge el nombre de archivo, deja un espacio vacío, deja un silencio, que, como dice Spivak, es preciso aprender a interpretar. En este caso, vemos que el poeta está marcando una diferencia: el nombre científico del pehuén, araucaria araucana, corresponde a la lógica occidental de dividir para entender, clasificando el mundo en reinos, familias y especies, separando de manera ontológica por sobre una aplicada o cultural.

Esta metodología resulta contradictoria con la visión de mundo del pueblo Mapuche. Tradicionalmente se la designa como "cosmovisión" como un modo de diferenciar culturas analógicas con el modelo racional, científico occidental, que encierra la ilusión de no derivarse, igualmente, de una "cosmovisión". La Mapuche, a diferencia de la cosmovisión occidental moderna, es holística y entiende que "monge, la vida humana [...] conlleva la idea de giros o vueltas repetitivas de algo con lo mismo, es decir, la estructura cíclica [...] que se repite siempre en todas las formas vivientes de la naturaleza" (Mora 71, cursiva en el original).

La violencia de imponer un nombre, borrando las señas identitarias de la cultura previa, parece haberlo entendido el poeta. Así, en tono épico y acorde con la prosopopeya que elabora, Neruda personifica a la araucaria dirigiéndole la palabra directamente para alabar su "valor resurrecto". En la construcción de la prosopopeya, entendemos que si el valor se celebra por resurgir en el presente de la enunciación, esta nos indica que hubo un tiempo en que estuvo ausente y es precisamente en esa dimensión donde se establece la pertinencia de la prosopopeya.

En "El código cifrado de la naturaleza", Ziley Mora transcribe el relato de un anciano Mapuche que cuenta cómo para ellos era posible "leer" en los árboles. Mora dice:

en estas palabras [las del anciano Mapuche] está contenida la última revelación del ecosistema austral en torno a la transcendencia que esconde el bosque nativo para el hombre de la tierra [el Mapuche]. Se trata de una noción ya perdida en la tradición cultural de occidente: la del árbol como oráculo; el árbol como vehículo de la revelación de poderes superiores del cosmos (69 y 70). 
Andrea Casals, Pablo Chiuminatto. Hablar por otros: Variaciones de la personificación en dos odas de Pablo Neruda

Mora explica que en la cosmovisión Mapuche el árbol es un altar, una columna sacra, “donde se manifiesta la protección divina” (70). En "Oda a la araucaria araucana” vemos la sintonía de Neruda con este culto. El poeta enuncia un desplazamiento que va del árbol al fruto (el poema dice araucaria cuando quiere decir piñón), del piñón al pan (menciona el fruto cuando quiere decir alimento). En De Certeau, un fruto que se come es ya un alimento culturizado, porque es en una determinada comunidad -cultura- que aprendemos qué se come y de qué modo se come (crudo, preparado, etc.). El pan es la metáfora del origen de la patria: "los piñones: / harina, pan silvestre / del indomable / Arauco" (14); "cayó / una marejada / de piñones / [...] / y desgranaron / su fruta, el pan postrero / de la patria" (16); "Araucaria, / [...] / gracias te dio / la ensangrentada estirpe / [...] / pan de valientes, / alimento escondido / en la mojada aurora /de la patria" (17); "del antiguo / y huracanado viento / de mi patria" (18). En otras palabras, si anteriormente en el poema "el racimo de tu especie" es el pueblo Mapuche, ahora el piñón es el pan, y este pan es el mismo pueblo Mapuche que ha comido de él y al hacerlo, asimila sus atributos. Como la levadura del pan, el pueblo Mapuche se levanta en defensa de su patria. Entendiendo que esta misma metáfora del pan que se leuda, y el ser humano que se levanta contra la injusticia, ha sido trabajada por Neruda en la "Oda al pan". En ambos casos, el vate relata una épica donde el trabajador, en este caso el pueblo originario, se levanta contra el conquistador, contra "[1]a cruz, la espada, el hambre" (15), contra todo el horror que trajo la conquista, para legar su sangre y su carácter a la fundación de una nación imposible.

Aquí la crisis de la representación que planteamos para ambas odas se muestra en el problema de traducción o traslación que se ejerce en las equivalencias que el mismo poeta instala. Desde la primacía de la letra escrita en la oda, desde la elegía a una materia que es nombrada con la voz de la misma cultura que la silencia, los subordinados son nombrados, por la misma estructura poética en la que el hablante se ofrece no solo como escriba y rapsoda sino también como mártir o caudillo. Es así como se vuelve imposible separar ese rol combinado de poeta y político que Neruda ejerce desde su poesía más temprana. Sin embargo, en los matices de la metagoge y de la prosopopeya va surgiendo algo más complejo que la lucidez de su mirada que da voz al que no tiene y que resulta de la combinación ideológica y artística en la que el poema cruza ambos territorios, tanto del autóctono como del extranjero, en una difícil fusión. 
Continuando, en la repetición "por tu fruta cerrada / por tu piñón abierto" (14) encontramos una aparente contradicción, no obstante, la fruta está cerrada. Los conos en los que crecen protegen la semilla en su interior, mientras que el piñón, la semilla misma, es la que el árbol entrega en otoño para fecundar la tierra y alimentar a su gente ${ }^{19}$. De acuerdo a lo enunciado en el poema, durante la Guerra de Arauco, cuando los Mapuche estaban al borde de sus fuerzas, resistiendo la conquista, la araucaria soltó su fruto en el bosque, y así el pueblo pudo alimentarse, fortalecerse y enfrentar al enemigo con espíritu renovado. Con esta imagen enunciada en el poema comprobamos nuevamente que el testigo que habla es un conocedor de la cultura Mapuche, ya que sabe que los árboles son un canal de conexión con la divinidad protectora de los seres humanos (Mora 70). Esta idea del alimento que llega en el momento de mayor vulnerabilidad es también una realidad cotidiana retratada en el relato del Lonco Pascual Coña, que en el capítulo II de Testimonio de un cacique Mapuche describe que cuando se les acababan los frutos de sus cultivos y cosecha, recurrían a la generosidad de la tierra: "No habiendo ya de qué vivir, la gente buscaba en los campos los necesario para mantener a los miembros de la familia. Fueron a buscar diferentes yerbas [...] De la cordillera se buscaban los muy apetecidos piñones" (en Mora 30 y 31).

La lluvia de piñones descrita en el poema no sólo nutre, sino que permite invertir la situación de vulnerabilidad en que se encontraban en el momento de la conquista; como dice de Certeau, "este cuerpo que tiene hambre [...] sueña sin término con una sociedad imposible, con una abundancia que invertiría la ley común de las proporciones” (178). Imagen que hace eco del relato del Éxodo de los israelitas por el desierto, cuando Dios les envía cada noche una lluvia de maná (16:31); imagen, nuevamente en un ejercicio de paralelismo, se actualiza en la popular canción de Juan Luis Guerra, “Ojalá que llueva café en el campo" (1989), simbolizando la abundancia que liberaría al campesino de la pobreza y opresión en que vive. Del mismo modo como en Chile, en Colombia, la épica del poema o la canción remiten al sueño redentor de un giro en el asedio de los conquistadores españoles y luego los ejércitos de "pacificadores" que la modernidad aportó.

\footnotetext{
${ }^{19}$ De acuerdo a la descripción de Adriana Hoffmann: "[1]a araucaria tiene flores masculinas y femeninas separadas [...] las femeninas, esféricas, y dispuestas en los extremos de las ramas nuevas, son grandes conos [...] en cuya base se hallan los óvulos; las masculinas están constituidas por amentos que producen gran cantidad de polen. La polinización se produce a través del viento [....] El [fruto es] el mismo cono de la flor femenina, que se lignifica y endurece, protegiendo a la semilla en su interior. Durante el otoño siguiente los conos se abren y diseminan las semillas (piñones) [....] Las semillas o piñones son comestibles y tienen un alto contenido energético [...] Constituyen la base de la dieta de los araucanos" (48).
} 
Andrea Casals, Pablo Chiuminatto. Hablar por otros: Variaciones de la personificación en dos odas de Pablo Neruda

Lamentablemente, la situación aludida no deja de tener otra resonancia actual menos festiva, justamente porque estas odas proclaman una reivindicación para el pueblo Mapuche que, en cierta medida, sigue sin respuesta. A pesar de que lo que sí está claro es que las comunidades han alcanzado al menos una voz poética reconocida, una que no podemos simplemente reducir a la misma que intentaba Neruda, pensando en poetas como Mabel Mora, Adriana Paredes Pinda, David Añiñir, Elicura Chihualaf o Jaime Huenun, entre otros. De alguna manera, hoy, se forma un frente insospechado que tiene que ver con el encuentro efectivo entre las propias voces de esas comunidades y estos proto-discursos identitarios que en la actualidad se vuelven relativos, precisamente por representar una voz ajena a las propias culturas originarias. A pesar de eso, estas odas no hablan solo de las pérdidas de antaño, sino que tienen vigencia hasta nuestros días. Más de un siglo después de la llamada Pacificación de Arauco y más de sesenta años después de la denuncia poética hecha por Pablo Neruda, la posición desde la cual enuncian sus reclamos las comunidades Mapuche no es la misma ya, si bien las reivindicaciones no han logrado un acuerdo representativo de sus propias colectividades.

A la sazón hay representantes de estas comunidades que hablan por ellas mismas, no es necesario un otro que se ofrece para hablar por el pueblo Mapuche, como lo hizo el poeta, sino que ellos mismos establecen el "acto que habla" (Spivack, 2120). Es decir, un gesto que dice por sí mismo y que tiene sentido en la esperanza de que el sacrificio histórico y el diálogo actual también dará sus frutos, como los dio el sacrificio del pehuén en su momento: “Así la Araucanía / recompuso / sus lanzas de agua y oro, [...] bajo el silbido / del valor / resurrecto / y avanzaron" (16). En este sentido, en la oda vemos un doble sacrificio, una asimilación, y la resurrección cultural. Parafraseando a Kristeva, como hemos visto, al recibir el alimento, también se reciben las cualidades del alimento ofrendado, y de este modo el ser que se sacrifica, vive en el otro: "No hay identificación idealizadora sin asesinato del objeto amado" (127). La araucaria entrega su fruto, muriendo el piñón al ser ingerido, muriendo en la certeza de que se hará vida en otros, en este caso, claramente la comunidad Pehuenche. Una vez que reciben el alimento, los hijos del pehuén experimentan nuevas fuerzas y estas les permiten, en una identificación con la entrega ejercida por el alimento recibido, arrojarse con valor y espíritu renovado al sacrificio, que confían no será en vano. El 
piñón ha sido entregado en alimento, así también ellos se entregaron y se entregan actualmente en el combate contra la tachadura de su cultura y su pueblo.

\section{La semilla fruto y pabellón patrio}

Al igual que en la parábola cristiana de la semilla: "Si el grano de trigo no cae a la tierra y muere, queda solo; pero si muere, da mucho fruto" (Jn 12, 24). La fruta cae al suelo, se sacrifica, para generar vida. Del mismo modo en la cultura Mapuche, así como en otras, esta misma dinámica asegura el ciclo. Es la muerte del fruto para la ingesta de otro, como plantea Korsmeyer, "El acto de la comida tiene que ver con la muerte [...] Acechando en el trasfondo de cualquier acto de comer, se puede descubrir que lo que se destruye o consume pierde su propia identidad mientras ayuda a mantener al otro" (253). Este es el mito que Neruda recoge de la fundación de una nación mestiza, la chilena, donde, como es apreciable, se funde una mirada cristiana con aquella autóctona, manifiesta en la crisis terminológica de los propios elementos autóctonos. En los versos "y dejó / sobre / la mojada tierra / los piñones" (14) y "se rompió contra la tierra, contra / la piedra defendida / y desgranaron / su fruta, pan postrero / de la patria" (16) encontramos la metáfora del origen, fecundación y proliferación de la patria, que se constituye en un mismo pueblo por el alimento común, como la sangre común, representado en el "pan de valientes, / alimento / escondido / en la mojada aurora / de la patria" (17). Nuevamente aquí se hace presente contradictoriamente lo que el poema busca denunciar, en este caso la imposición terminológica del estado nación, que el propio concepto de comunidad del mundo Mapuche rechaza.

Revisemos esta idea del origen de la patria. En esta oda, la araucaria también es aludida por medio de las metáforas "pabellón del invierno" y "poderoso pabellón". Vale destacar que la palabra pabellón tiene varias acepciones que hacen sentido en el contexto del poema. De acuerdo al uso, en el Diccionario de la Real Academia Española, pabellón designa una " $[t]$ ienda de campaña en forma de cono, sostenida interiormente por un palo grueso hincado en el suelo y sujeta al terreno alrededor de la base con cuerdas y estacas" (1643a). Esta descripción es asimilable a las características físicas, concretas y materiales de la araucaria, evocando su forma y la experiencia de estar cobijado debajo de una de ellas. Otra acepción de pabellón dice que puede ser un adorno para un trono o un altar, o una bandera, siendo esta imagen coherente con la relevancia que tiene el árbol en la cosmovisión 
Mapuche, sugiriendo el emblema que representa a los pueblos nativos del sur de Chile, y que -aunque posterior a la publicación de este poema- ha sido declarado monumento nacional ${ }^{20}$. Por otra parte, un pabellón también puede ser un "[g]rupo de fusiles que se forman enlazándolos por las bayonetas [...]" (1643a), sugiriendo el estado de guerra y resistencia al que alude el poema. Finalmente, un pabellón también es un "[e]dificio que constituye una dependencia de otro mayor, inmediato o próximo a aquel" (1643a), de tal manera que se prefigura la independencia del pueblo Mapuche al interior del estado Chile ${ }^{21}$. En otras palabras, cuando el hablante dice pabellón, está aludiendo a todas estas acepciones de la palabra, como dice Mora, desgranándola en un estallido de significado: si el pabellón es el emblema que representa al pueblo Mapuche, la araucaria representa la soberanía, así como una bandera representa una nación. En la heráldica de esta representación están el cobijo y la complicidad sagrada de la araucaria con el pueblo Mapuche, el fruto que alimenta y reúne a las comunidades y le da su identidad como tal, la historia de lucha contra el conquistador, y la vinculación territorial que la materialidad de la araucaria tiene. En definitiva, la identidad de una posible nación Mapuche, pero bajo principios diferentes a los que identifican el principio de verticalidad, unión e individualidad que dicho concepto encierra para Occidente principalmente luego que los conquistadores "pelearon entre sí por el reparto del Nuevo Mundo" (Smith 61).

En esta misma línea, en ambas odas encontramos repeticiones que aluden a la patria. En "Oda al trigo de los indios", figuran: "Araucanos, / padres / de la nación” (173) y “pidiendo patria” (174). Así el hablante está reconociendo o imaginando una soberanía de los Mapuches como primeros ocupantes de la Araucanía, pero también, como otras voces lo harán a lo largo de ese mismo siglo, reconoce que han sido excluidos del sistema dominante de conformación de la nación chilena, y por tanto, ahora piden patria (Aylwin 8). En "Oda a la araucaria araucana" aparecen: "pabellón de invierno" (14) y "poderoso pabellón” (16), “torre de Chile" (14), "pan postrero de la patria", y "voy con mis banderas" (16). Todas estas

\footnotetext{
${ }^{20}$ La declaración del pehuén como monumento nacional en 1976 contribuye a su preservación ya que prohíbe la tala. Sin embargo, su estado actual es en peligro de extinción. En el presente (2017), científicos de la Universidad de la Frontera han iniciado la tramitación ante el Ministerio del Medio Ambiente para cambiar su estado de "vulnerable" a "en peligro de extinción". Las causas visibles: los incendios forestales de 2015 en China Muerta y la cosecha indiscriminada del pehuen por personas no Mapuche. Podríamos agregar que el aumento de las temperaturas también influye en el equilibrio de su ecosistema.

21 "Las comunidades [Mapuche] empobrecidas y hacinadas demandan la reparación de una herida histórica mediante el aumento de sus tierras y el derecho a decidir su destino como pueblo y a desarrollar en sus territorios plenamente su vida, ejerciendo sobre ellos una responsable autonomía". (Editorial, Mensaje, 6)
} 
repeticiones giran en torno al emblema patrio y nos dan la clave para descifrar la metáfora que está detrás: el hablante reconoce una cultura Mapuche representada en el pehuén que es la "torre de Chile" (por su forma) o "pabellón de invierno" (por su área geográfica). Establece así la relación entre este pueblo y la naturaleza, especialmente con los árboles, que no solo, como en el caso de la araucaria le da el alimento, sino que también es un canal de conexión con las divinidades y un elemento protector como hemos visto. En otras palabras, lo que el poeta está pidiendo es una forma de soberanía para el pueblo Mapuche, que significa concreta y materialmente tierras, con las cuales no solo se revierte la situación de pobreza, sino que también la borradura identitaria que habrían sufrido "las personas de la tierra". Al mismo tiempo, el hablante traduce en términos de la única forma de soberanía que conoce: la occidental. Así, propiedad, estado nación y unidad cultural, emergen como los conceptos centrales. Desde el reconocimiento actual de la multiculturalidad que acoge el territorio chileno -con al menos nueve etnias reconocidas- a riesgo de errar en la traducción, hoy podemos entender la petición como el reconocimiento de la nación Mapuche dentro del estado chileno, la plurinacionalidad, donde el pueblo Mapuche pueda autoadministrar y vivir su cultura. Todos convidados a la gran mesa que imagina el poema, dignos comensales.

"Deja caer / en mi alma / tus granadas / para que las legiones / se alimenten / de tu especie en mi canto" (18) es una manera metafórica en que la voz pide permiso para hablar por el pueblo Mapuche para que todo Chile conozca y se nutra de este mito gestacional, y se contagie del carácter de su épica: "porque a la misma luz de hojas y / aurora, / arenas y follajes, / yo voy [tiempo presente] con las banderas" (18).

En la culminación del poema descubrimos cómo decir “Araucaria araucana” es lo mismo que decir "pueblo Mapuche", porque dicha cultura no se puede entender sin un territorio ( $\mathrm{su}$ autodesignación, mapu-che 'gente de la tierra'). El poema plantea un desplazamiento, al decir "Araucaria araucana" quiere decir "pueblo Mapuche”, y en una sinécdoque, "Araucaria araucana" correspondería a decir "Araucanía": "yo voy con las banderas / al llamado / profundo de mi pueblo! / Araucaria araucana, / aquí me tienes!” (18), canta el poeta. La interposición de la persona y la personificación en el poema se fusionan. El hablante pertenece a la etnia, más allá del poema, del poeta. 


\section{Conclusión}

A modo de cierre, podemos afirmar que en estas dos odas está presente de forma compleja y de alguna manera sesgada, como matriz, la definición de una justicia apropiada para el pueblo Mapuche que va más allá de la devolución de sus tierras y de su reconocimiento como nación. Sin embargo, esto es manifiesto no solo en lo que alude el poema sino en la crisis terminológica y retórica en la que se engasta. Por una parte, los conceptos occidentales en que se expresa, además de los valores en los que traduce la ambición de esa otra cultura que debe necesariamente ser la misma que la heredada por la Paideia griega, en la aceptación de las formas de gobierno y la administración que la cultura occidental ha organizado la civilización. En otras palabras, habla de justicia cuando menciona el alimento, pero habla de un alimento ligado a la tierra y a la historia del pueblo Mapuche, como una unidad, por lo tanto, habla de la identidad cultural de la "gente de la tierra" que se construye en torno a dicho alimento (representado en el piñón que nace del pehuén) y particularmente a la tierra. En definitiva, esta es la patria de la que quiere hablar el poeta cuando se diferencia de Alonso de Ercilla, anunciando en el poema la noticia de que "otro poeta viene cantando". Aunque nuevamente la épica que alcanza solo anuncia una nueva metagogé forzada y una prosopopeya unitaria que hace crisis en el poema mismo.

\section{Bibliografía}

Agamben, Giorgio. "El archivo y el testimonio". Vol. III. Homo Sacer. Lo que resta de Auschwitz: El archivo y el testigo. Valencia: Pre-textos 2000. Impreso.

Alighieri, Dante. Divina Comedia. Madrid: Cátedra, 2009. Impreso.

Aylwin, José. "Deuda con el pueblo Mapuche: Herida abierta en el Bicentenario". Revista Mensaje, 593, Octubre (2010): 8-10. Impreso.

Bengoa, José. "Chile y los Mapuches: asignaturas pendientes". Revista Mensaje, 583, Octubre (2009): 40-43. Impreso.

Chiuminatto, Pablo. "Ecos de una crisis. Hacia la creación de un Ministerio de Cultura". Revista Estudios Públicos, 145, verano (2017): 141-165.https://www.cepchile.cl/ecosde-una-crisis-hacia-la-creacion-de-un-ministerio-de-cultura/cep/2017-21/102621.html

Certeau, Michel De, Luce Giard y Pierre Mayol. La invención de lo cotidiano. 2. Habitar, cocinar. México: Universidad Iberoamericana, 1999. Impreso. 
Concha, Jaime. "El descubrimiento del pueblo en la poesía de Neruda". Tres ensayos sobre Pablo Neruda. Palma de Mallorca: Hispanic Studies, 1 (1974) 85-95. Impreso.

Coña, Pascual. Testimonio de un cacique Mapuche. $5^{\mathrm{a}}$ ed. Chile: Pehuén, 1995. Impreso.

Ercilla y Zúñiga, Alonso De. La Araucana. Madrid: Cátedra, 1998. Impreso.

Figueroa, Aída. A la mesa con Neruda. Toledo: Mondadori, 2000. Impreso.

Han, Byung-Chul. La sociedad del cansancio. Barcelona: Herder, 2012. Impreso.

Hoffmann, Adriana. Flora silvestre de Chile; zona araucana. $4^{\mathrm{a}}$ ed. Santiago: Ediciones Fundación Claudio Gay, 1982. Impreso.

Korsmeyer, Carolyn. "Relatos de comida". El sentido del gusto: Comida, estética y filosofía. Barcelona: Paidós, 2002. Impreso.

Kristeva, Julia. "Dios es ágape". Historias de amor. México: Siglo XXI, 2000. Impreso.

McCard, Victoria. "El banquete nerudiano". Literatura y Lingüística, 10 (1997). http://redalyc.uaemex.mx/pdf/352/35201001.pdf

Mistral, Gabriela. "Maíz". Tala, 1938. Gabriela Mistral en verso y prosa: Antología. Real Academia Española, ed. Perú: Alfaguara. 2001, 217-276. Impreso.

Montecino, Sonia. Mitos de Chile. Diccionario de seres, magias y encantos. Santiago: Editorial Sudamericana, 2003. Impreso.

Mora, Ziley. "El código cifrado de la naturaleza". La tragedia del bosque chileno. Hoffmann, Adriana. Santiago: Ocho libros editores. 1998: 69-72. Impreso.

Neruda, Pablo. "América". Canto general, 1950. Pablo Neruda; Antología general. Real Academia Española, ed. Perú: Alfaguara. 2001. Impreso.

------. Confieso que he vivido. Memorias. $1^{\mathrm{a}}$ ed. Barcelona: Seix Barral, 1974. Impreso.

-------. Confieso que he vivido. Memorias. $2^{\text {a }}$ ed. Santiago: Planeta, 1992. Impreso.

-------."Está de moda comer". Comiendo en Hungría, 1965. Figueroa, Aída. A la mesa con Neruda. Toledo: Mondadori, 2000. Impreso.

-------."Estatuto del vino". Residencia en la tierra. $3^{\text {a }}$ ed. Barcelona: Planeta, 1989. Impreso.

-------Nuevas odas elementales. Argentina: Losada, 1955. Impreso.

-------.'Oda al pan”. Odas elementales. Buenos Aires: Seix Barral, 1992. 183-187. Impreso.

Nixon, Rob. Slow Violence and the Environmentalism of the Poor. Harvard University Press, 2011. Impreso.

"Pueblos indígenas: derechos, territorio, autonomía". Editorial. Revista Mensaje, 583. Octubre (2009): 6. Impreso.

Real Academia Española. Diccionario de la lengua española. Madrid: 2011. Impreso.

Riffaterre, Michel. Semiotics of poetry. Bloomington: Indiana University Press, 1984. Impreso.

Riffaterre, Michael. "Modelos Hermenéuticos." Cyber Humanitatis, 31 Invierno (2004). http://www.cyberhumanitatis.uchile.cl/CDA/texto_sub_simple2/0,1257,PRID\%253D 14079\%2526SCID\%253D14082\%2526ISID\%253D499,00.html.

Schmith, Carl. Tierra y Mar: una reflexión sobre la historia universal. Madrid: Trotta, 2007. Impreso.

Schoennenbeck, Sebastián. "La bruja y la ruptura de un orden en El obsceno pájaro de la noche de José Donoso". Revista Anales de literatura chilena. 10 (2009): 161-175. http://analesliteraturachilena.letras.uc.cl/images/N11/a11_8.pdf

Sepulveda, Magda. "Para una entrada en la imaginación poética alimentaria chilena". Revista Chilena de Literatura, 86 (2014): 199-213. http://revistaliteratura.uchile.cl/index.php/RCL/article/view/31500/33259 
Soto, David, Juan Fuenzalida y Carlos Bresciani. "Justicia y paz en territorio Mapuche". Revista Mensaje, 657. Marzo-Abril (2017): 34-6. Impreso.

Spivak, Gayatri. A Critique of Postcolonial Reason: Toward a History of the Vanishing Present, 1999. The Norton Anthology of Theory and Criticism. $2^{\mathrm{a}}$ ed. New York: Norton. 2010. Impreso.

"Mineros graban video y muestran cómo viven en el refugio" originalmente en Terra.cl, 27 agosto 2010. Actualmente en AFP. Búsqueda: http://www.prensalibre.com/odiseabajo-tierra/figuras-emblematicas-mineros-soterrados-0-352764853

Whitman, Walt. Leaves of Grass, 1891-92. The Northon Anthology of Poetry. $5^{\text {a }}$ ed. New York: Norton. 2005. Impreso.

Yaksic, Miguel. "Mapuches, chilenos y el sentido de la política”. Revista Mensaje, 583. Octubre (2009): 36-39. Impreso. 